\title{
Systematic review and meta-analysis of aortic valve-sparing surgery versus replacement surgery in ascending aortic aneurysms and dissection in patients with Marfan syndrome and other genetic connective tissue disorders
}

\author{
Maria Elena Soto ${ }^{1,2}$, Eric Ochoa-Hein ${ }^{3}$, Javier E. Anaya-Ayala ${ }^{4}$, Micaela Ayala-Picazo ${ }^{5}$, \\ Solange Gabriela Koretzky ${ }^{6}$
}

${ }^{1}$ Instituto Nacional de Cardiologia Ignacio Chavez, Mexico City, México; ${ }^{2}$ American British Cowdray Medical Center, Mexico City, México; ${ }^{3}$ Hospital Epidemiology Department, Instituto Nacional de Ciencias Médicas y Nutrición Salvador Zubirán, Mexico City, México; ${ }^{4}$ Section of Vascular Surgery and Endovascular Therapy, Surgery Department, Instituto Nacional de Ciencias Médicas y Nutrición Salvador Zubirán, Mexico City, México; ${ }^{5}$ Library Department, American British Cowdray Medical Center, Mexzico City, Mexico; ${ }^{6}$ Editorial Department, Instituto Nacional de Cardiologia Ignacio Chavez, Mexico City, Mexico

Contributions: (I) Conception and design: ME Soto, JE Anaya-Ayala, E Ochoa-Hein; (II) Administrative support: ME Soto; (III) Provision of study materials or patients: ME Soto, M Ayala-Picazo; (IV) Collection and assembly of data: ME Soto, E Ochoa-Hein, JE Anaya-Ayala, SG Koretzky; (V) Data analysis and interpretation: ME Soto, JE Anaya-Ayala, E Ochoa-Hein; (VI) Manuscript writing: All authors; (VII) Final approval of manuscript: All authors.

Correspondence to: Maria Elena Soto. Instituto Nacional de Cardiologia, Juan Badiano 1 Col. Seccion XVI, Mexico City, Mexico; American British Cowdray Medical Center Observatorio, Sur 132 Col. Las Americas, Mexico City, Mexico. Email: mesoto50@hotmail.com.

Background: Aortic aneurysm and dissection are important causes of morbimortality in patients with Marfan syndrome (MFS) and other connective tissue diseases that affect the cardiovascular tissues. Timely intervention through different surgical techniques improves the prognosis. Both sparing and replacementtype interventions of the aortic valve are used, but selection depends on the condition of the patient at the time of diagnosis, the patient's emergency condition, surgeon preference and hospital resources. Previous meta-analyses have suggested an advantage with the use of sparing-type interventions, but this finding must be updated and extended to patients with other connective tissue disorders. The objetive of this study is to evaluate the outcomes of valve-sparing root replacement versus aortic root replacement procedures in patients with MFS and similar connective tissue diseases that present with aortic aneurysm or dissection.

Methods: A systematic review of cohort studies that evaluated sparing-type (preserving, remodeling, reimplantation, Yacoub, David or Florida Sleeve) or replacement-type (repair, Bentall, Button-Bentall, composite valve graft or Cabrol) procedures in patients with Marfan, Loeys-Dietz, Beals-Hecht or EhlersDanlos syndromes was done. Studies were retrieved from the SCOPUS, MEDLINE, CINAHL, EMBASE and LILACS electronic databases up to January 2020 without language restrictions. Only studies that directly compared sparing- versus replacement-type procedures were included in the meta-analysis.

Results: A total of 33 studies ( $\mathrm{n}=1,807$ subjects) reported sparing-type surgical interventions and 26 studies ( $n=2,218$ subjects) reported replacement-type surgical interventions. Pooled rates of endocarditis, thromboembolism and aneurysm were higher in replacement-type surgical intervention studies. Sixteen studies were included in the meta-analysis. Sparing-type interventions were associated with a reduced risk of endocarditis ( $\mathrm{RR}=0.13$, 95\% CI: 0.03-0.61); however, replacement-type interventions favored freedom from valve reoperation $(\mathrm{RR}=2.39,95 \% \mathrm{CI}: 1.24-4.60)$. All studies were at low risk of bias.

Conclusions: The choice of the best surgical technique is dependent on the type of disease (MFS or other connective tissue diseases) as well as the accompanying aortic and cardiovascular damage, since these key factors are heterogeneous. Although the results of this meta-analysis tend to show some advantages for one type of surgical intervention over the other and viceversa, the surgeon can only make the best decision during the surgical act. 
Keywords: Marfan syndrome (MFS); connective tissue disorders; aortic aneurysm; aortic dissection; surgical technique

Submitted May 07, 2021. Accepted for publication Jul 15, 2021.

doi: $10.21037 /$ jtd-21-789

View this article at: https://dx.doi.org/10.21037/jtd-21-789

\section{Introduction}

Of the connective tissue diseases that affect the cardiovascular system, Marfan syndrome (MFS) is more common than other genetic conditions or similar syndromes (SS). MFS, an autosomal dominant genetic disease, is caused by a mutation of the fibrillin-1 gene, a major glycoprotein of the extracellular matrix, which leads to the deterioration of the connective tissue. The ocular and skeletal systems are also affected in MFS (1-4).

Loeys Dietz Syndrome (LDS) is associated with mutations in the genes of transforming growth factor 1 and 2 (TGFBR1 and TGFBR2). Although LDS is similar to MFS, LDS patients can present with aortic dilation that progresses rapidly to aortic dissection; therefore, differential diagnosis is essential because this can influence the timely surgical decision (5).

Also, aortic dilation progresses rapidly in other SS, such as type IV Ehlers-Danlos syndrome, which is characterized by a mutation in a gene that encodes collagen chains (6-8).

Different cardiovascular conditions such as valve disease, aortic dilation, aneurysm and dissection are cardiovascular complications associated with decreased survival in patients with MFS and SS, especially when diagnosis is late.

Improvements in the treatment of aortic damage were not feasible until synthetic grafts that allow the vascular segment to be replaced were manufactured and commercialized in the late 1950s (9). Since then, various surgical techniques have been developed to replace the affected segment. For instance, Mueller reported the supracoronary replacement technique in 1960 (10), Starr and collaborators published the supracoronary replacement and that of the aortic valve in 1963, and Wheat et al. described a radical technique of resection of the aortic wall in 1964 (11). It was not until 1968 that Bentall and De Bono described the technique to replace the ascending aorta and the aortic valve with a graft containing a valvular prosthesis with lateroterminal reimplantation of the ostium of the coronary arteries (12).

In the last 50 years, "prophylactic" surgery with replacement of the aortic root has gained popularity among surgeons because it entails less risk to and improves survival in patients with aortic aneurysms.

In patients with MFS who have an aneurysm of the aortic root, the valve preservation procedure (David) has been increasingly used because it is thought of as a technique that offers better results (13); however, the pre-surgical condition of the patient, the duration of surgery and the type of postoperative complications affect the outcomes.

Overall results of surgery depend on the general condition of each patient, the number of dilated aortic segments, the diameter of the affected segments and the presence or absence of dissection; however, associated valvular damage and other cardiovascular conditions can also influence the outcome. Furthermore, surgical technique and whether the intervention is urgent or elective are factors that may interfere with the results. The literature describes the association between different surgical techniques and outcomes used in MFS patients, but few include the wide array of patients with SS.

The heterogeneity between the different surgical techniques and connective tissue diseases has made it very difficult to draw conclusions about the performance and impact of each surgical technique on the outcomes relevant to these conditions. Knowledge of more specific data could broaden the evidence needed to guide the selection of a particular surgical technique. Consequently, we performed a systematic review and meta-analysis to determine the results of the different surgical techniques used in patients with different connective tissue diseases that present with aortic dilation or dissection.

We present the following article in accordance with the PRISMA reporting checklist (available at https://dx.doi. org/10.21037/jtd-21-789).

\section{Methods}

\section{Data sources and search}

With the assistance of a librarian (MA), potentially relevant 
articles were identified by searching EMBASE, MEDLINE, CINAHL/EBSCO, LILACS, OVID, KOREAMED and COCHRANE LIBRARY SCOPUS electronic databases up to January 2020 without any language restrictions. The search strategy was operated in MEDLINE with use of MeSH terms (Table 1).

All articles and abstracts (including unpublished doctoral theses) that fulfilled the (PICO) criteria were included for further analysis: $(\mathrm{P})$ population: MFS, Loeys-Dietz syndrome, Beals-Hecht syndrome, Sprintzen-Goldberg syndrome or Ehlers-Danlos syndrome patients of any age and gender with thoracic aortic aneurysm and/or dissection; (I) intervention: valve-sparing root replacement (VS) (preserving, remodeling, reimplantation, Yacoub, David or Florida Sleeve) or replacement procedure (VR) (repair, Bentall, Button-Bentall, composite valve graft or Cabrol); (C) comparator: VS or VR, as appropriate; and (O) outcomes: in-hospital mortality (before hospital discharge), late mortality (occurring $>30$ days after hospital discharge), stroke, acute myocardial infarction, aortic insufficiency, endocarditis, thromboembolic events, bleeding, arrhythmia, dissection, aneurysm and reintervention due to bleeding or for valve repair. Both retrospective and prospective cohorts were acceptable study designs. Care was taken to select the articles that fulfilled the standards set in the Strengthening the Reporting of Observational Studies in Epidemiology (STROBE) statement (14). A study was excluded if: (I) it was a duplicate report or an update from a previous cohort, (II) it reported data that were not stratified by syndrome and surgical technique, or (III) it reported outcomes solely in a graphical format. Concomitant surgical interventions (such as coronary-artery bypass grafting or mitral valve repair) were not considered exclusion criteria. Previous meta-analyses were identified and any missing studies not retrieved during the previous steps were included and analyzed as mentioned above.

Three investigators (MES, EO and JA) independently reviewed all citations identified through the literature search using a predefined protocol. Articles that did not meet inclusion criteria during the title and abstract analysis were excluded. The remaining articles were selected for full text review. When limited information was available from the abstract, the full text was always obtained. Included articles underwent a quality assessment by four investigators (MES, EO, JA and SK).

Disagreements regarding the selection and quality assessment of articles were resolved through group discussion, and full consensus was achieved at each stage of review.
The study was submitted to PROSPERO, the international prospective register of systematic reviews of the National Institute of Health Research with the number: CRD42018103193.

\section{Data extraction}

Four investigators (MES, EO, JA and SK) independently extracted data from selected studies using a standardized electronic form. The following information was collected: author, year of publication, country, study design, total number of subjects, gender, mean age, type of disease, mean aortic diameter, number of urgent procedures, mean and total duration of follow-up, types of surgical techniques assessed, and the outcomes mentioned above. Whenever data were reported in percentages, conversion to integers was done multiplying the fraction by the total number of subjects in the category being analyzed. Since individual data were not available from any study, means and medians were handled as such, without modifications in our database.

\section{Summary of the systematic review}

A summary was made of all articles included in the systematic review and is reported separately for VS and VR interventions. Since patients of one group could have crossed over to the other group, subjects were classified in the group that corresponded to the first type of surgical intervention performed (analogous to an intention-to-treat analysis). Variables in nominal scale were summarized using percentages, whereas numerical variables were summarized using either medians and interquartile ranges (variables with non-gaussian distributions) or weighted means and weighted standard deviations (variables with gaussian distributions). Incidence density rates were calculated following two steps: first, the total number of events for each outcome of interest was divided by the sum of the person-years of the at-risk population in each study; second, those results were standardized to 10,000 person-years. Person-years were calculated by multiplying the total number of subjects included in each study by the mean follow-up (measured in years). Absent data were not replaced and precluded calculation of incidence density rates in these cases.

\section{Statistical analysis}

Testing of differences between groups at this step of the 
Table 1 CENTRAL search strategy

\begin{tabular}{|c|c|}
\hline No. & Strategy \\
\hline$\# 1$ & MASS syndrome ALL FIELDS \\
\hline \#2 & SUPPLEMENTARY CONCEPT MASS syndrome \\
\hline \#3 & MESH DESCRIPTOR Ehlers-Danlos Syndrome \\
\hline \#4 & Ehlers-Danlos Syndrome ALL FIELDS \\
\hline \#5 & Ehlers Danlos Syndrome ALL FIELDS \\
\hline \#6 & EHLERS DANLOS disease ALL FIELDS \\
\hline$\# 7$ & EHLERS-DANLOS disease ALL FIELDS \\
\hline \#8 & Loeys-Dietz Syndrome ALL FIELDS \\
\hline$\# 9$ & Loeys Dietz Syndrome ALL FIELDS \\
\hline$\# 10$ & $\begin{array}{l}\text { Loeys-Dietz Aortic Aneurysm Syndrome ALL } \\
\text { FIELDS }\end{array}$ \\
\hline$\# 11$ & $\begin{array}{l}\text { Loeys Dietz Aortic Aneurysm Syndrome ALL } \\
\text { FIELDS }\end{array}$ \\
\hline$\# 12$ & MESH DESCRIPTOR Loeys-Dietz Syndrome \\
\hline$\# 13$ & Marchesani Syndrome ALL FIELDS \\
\hline$\# 14$ & MESH DESCRIPTOR Weill-Marchesani Syndrome \\
\hline \#15 & Marchesani-Weill Syndromes ALL FIELDS \\
\hline$\# 16$ & Marchesani-Weill Syndrome ALL FIELDS \\
\hline$\# 17$ & Marchesani Weill Syndromes ALL FIELDS \\
\hline$\# 18$ & Marchesani Weill Syndrome ALL FIELDS \\
\hline \#19 & Beals Hecht syndrome ALL FIELDS \\
\hline \#20 & Beals-Hecht syndrome ALL FIELDS \\
\hline \#21 & Shprintzen-Goldberg syndrome ALL FIELDS \\
\hline \#22 & Shprintzen Goldberg syndrome ALL FIELDS \\
\hline \#23 & $\begin{array}{l}\text { Shprintzen-Goldberg Craniosynostosis Syndrome } \\
\text { ALL FIELDS }\end{array}$ \\
\hline \#24 & $\begin{array}{l}\text { Shprintzen Goldberg Craniosynostosis Syndrome } \\
\text { ALL FIELDS }\end{array}$ \\
\hline \#25 & Shprintzen Golberg craniosynostosis ALL FIELDS \\
\hline \#26 & $\begin{array}{l}\text { SUPPLEMENTARY CONCEPT Shprintzen Golberg } \\
\text { craniosynostosis }\end{array}$ \\
\hline \#27 & MESH DESCRIPTOR Marfan Syndrome \\
\hline \#28 & $\begin{array}{l}\text { MESH DESCRIPTOR Marfan Syndrome EXPLORE } \\
\text { ALL TREES }\end{array}$ \\
\hline \#29 & marfan: $\mathrm{TI}, \mathrm{AB}, \mathrm{KY}$ \\
\hline
\end{tabular}

Table 1 (continued)
Table 1 (continued)

\begin{tabular}{|c|c|}
\hline No. & Strategy \\
\hline$\# 30$ & $\begin{array}{l}\# 1 \text { OR \#2 OR \#3 OR \#4 OR \#5 OR \#6 OR \#7 OR } \\
\# 8 \text { OR \#9 OR \#10 OR \#11 OR \#12 OR \#13 OR } \\
\# 14 \text { OR \#15 OR \#16 OR \#17 OR \#18 OR \#19 OR } \\
\# 20 \text { OR \#21 OR \#22 OR \#23 OR \#24 OR \#25 OR } \\
\# 26 \text { OR \#27 OR \#28 OR \#29 }\end{array}$ \\
\hline \#31 & valve-sparing: ALL FIELDS \\
\hline \#32 & valve sparing: ALL FIELDS \\
\hline \#33 & bentall: ALL FIELDS \\
\hline \#34 & cvg: ALL FIELDS \\
\hline \#35 & david procedure: ALL FIELDS \\
\hline \#36 & aortic valve sparing: ALL FIELDS \\
\hline \#37 & aortic valve preserving: ALL FIELDS \\
\hline \#38 & aortic root replacement: ALL FIELDS \\
\hline \#39 & composite valve graft: ALL FIELDS \\
\hline \#40 & aortic root surgery: ALL FIELDS \\
\hline \#41 & Florida Sleeve: ALL FIELDS \\
\hline \#42 & $\begin{array}{l}\# 31 \text { OR \#32 OR \#33 OR \#34 OR \#35 OR \#36 OR } \\
\# 37 \text { OR \#38 OR \#39 OR \#40 OR \#41 }\end{array}$ \\
\hline \#43 & Remodeling root repair: TI \\
\hline \#44 & Valve-sparing root replacement: $\mathrm{TI}$ \\
\hline \#45 & Root remodeling: $\mathrm{TI}$ \\
\hline \#46 & Valve-sparing reimplantation: $\mathrm{TI}$ \\
\hline \#47 & Aortic valve-sparing root replacement: $\mathrm{TI}$ \\
\hline \#48 & Valve configuration: $\mathrm{TI}$ \\
\hline \#49 & \#43 OR \#44 OR \#45 OR \#46 OR \#47 OR \#48 \\
\hline$\# 50$ & aortic ring: $\mathrm{TI}$ \\
\hline \#51 & aortic valves: $\mathrm{TI}$ \\
\hline \#52 & Valve repair: $\mathrm{TI}$ \\
\hline \#52 & aortic regurgitation: $\mathrm{TI}$ \\
\hline \#54 & valves: $\mathrm{TI}$ \\
\hline \#55 & repair: TI \\
\hline \#56 & \#50 OR \#51 OR \#52 OR \#53 OR \#54 OR \#55 \\
\hline \#57 & \#49 AND \#56 \\
\hline \#58 & MESH DESCRIPTOR Cohort Studies \\
\hline \#59 & $\begin{array}{l}\text { MESH DESCRIPTOR Cohort Studies EXPLORE } \\
\text { ALL TREES }\end{array}$ \\
\hline
\end{tabular}

Table 1 (continued) 
Table 1 (continued)

\begin{tabular}{ll}
\hline No. & Strategy \\
\hline$\# 60$ & mid-term: ALL FIELDS \\
$\# 61$ & long-term: ALL FIELDS \\
$\# 62$ & cohort study: ALL FIELDS \\
$\# 63$ & cohort studies: ALL FIELDS \\
$\# 64$ & cohort: ALL FIELDS \\
$\# 65$ & \#58 OR \#59 OR \#60 OR \#61 OR \#62 OR \#63 OR \\
\#66 & \#64 \\
\#67 & \#50 AND \#42 AND \#65 \#66 \\
Filters & \\
Languages & Open \\
Article types & Open \\
$\begin{array}{l}\text { Publication } \\
\text { date }\end{array}$ & Open \\
\hline
\end{tabular}

analysis was done with either the chi-square test (nominal variables) or with the Student $t$-test/Wilcoxon rank-sum test, as appropriate (numerical variables); $\mathrm{P}$ values $\leq 0.05$ were considered statistically significant. Stata version 14.0 (StataCorp, College Station, TX, USA) was used.

The meta-analysis was done only for the studies that directly compared VS $v s$. VR interventions. Since differing follow-up times between study groups were commonplace, only outcomes with comparable follow-up times were deemed eligible for comparison. When subjects had 2 different types of surgical interventions during follow-up, categorization ensued as mentioned above. All outcomes that had at least two studies available for meta-analysis were finally reported. Risk of bias was assessed using RevMan version 5; categorization of overall risk of bias for each study proceeded as mandated by Cochrane standards. Risk ratios with their $95 \%$ confidence intervals were calculated for each outcome using the fixed effects model; $\mathrm{P}$ values $\leq 0.05$ and $95 \%$ confidence intervals that did not include risk ratio values equal to 1.0 were considered statistically significant. In case of significant heterogeneity ( $\geq 30 \%$ ), its cause was determined and corrected, and meta-analysis was repeated once again after this step using the fixed effects model. Finally, publication bias for each outcome was assessed using funnel plots and Egger's test. RevMan version 5 was used for all analyses except for Egger's test, which was done with Stata version 14.0.

\section{Results}

\section{Summary of systematic review}

Of the 41 included studies, 33 studies ( $\mathrm{n}=1,807$ subjects) reported outcomes for VS interventions and 26 studies ( $\mathrm{n}=2,218$ subjects) reported outcomes for VR interventions (Figure 1) (15). The majority of included studies had a retrospective cohort design. MFS patients comprised the majority of subjects included in both types of surgical interventions. Male subjects comprised more than $65 \%$ of subjects included in both interventions. No significant differences were noted in the aforementioned variables. However, subjects in the VS group were younger, had smaller aortic diameters, had a lower proportion of aortic dissection and had a higher proportion of elective interventions performed. These results are fully shown in Table 2.

Incidence density rates differed significantly between groups for the following outcomes: endocarditis, thromboembolic events and aneurysm (higher rates in the VR group). Results are further shown in Table 2.

\section{Meta-analysis}

A total of 16 studies were included in the meta-analysis: Bernhardt 2011 (16), Cameron 2009 (17), Coselli 2014 (18), de Oliveira 2003 (19), Gott 1999 (20), Karck 2004 (21), Moreau de Bellaing 2019 (22), Nicolò 2017 (23), Patel 2008 (24), Price 2016 (25), Roubertie 2009 (26), Schoenhoff 2015 (27), Sheick-Yousif 2008 (28), Song 2014 (29), Volguina 2009 (30), and Zehr 2005 (31). Only MFS patients were included (the number of other types of patients was too small for subgroup meta-analysis). All of the studies included in the most recent published metaanalysis [Hu 2014 (32)] were considered in the present one, except for Nardi 2010 (33) [which is included in the most recent report from Nicolò 2017 (23)]. A summary is offered in Table 3.

Results for the following outcomes were calculated.

\section{In-hospital mortality}

Seven studies were included [Cameron 2009 (17), de Oliveira 2003 (19), Gott 1999 (20), Karck 2004 (21), Roubertie 2009 (26), Sheick-Yousif 2008 (28), and Zehr 2005 (31)]. The overall risk ratio was $0.62(0.22-1.74)$. 


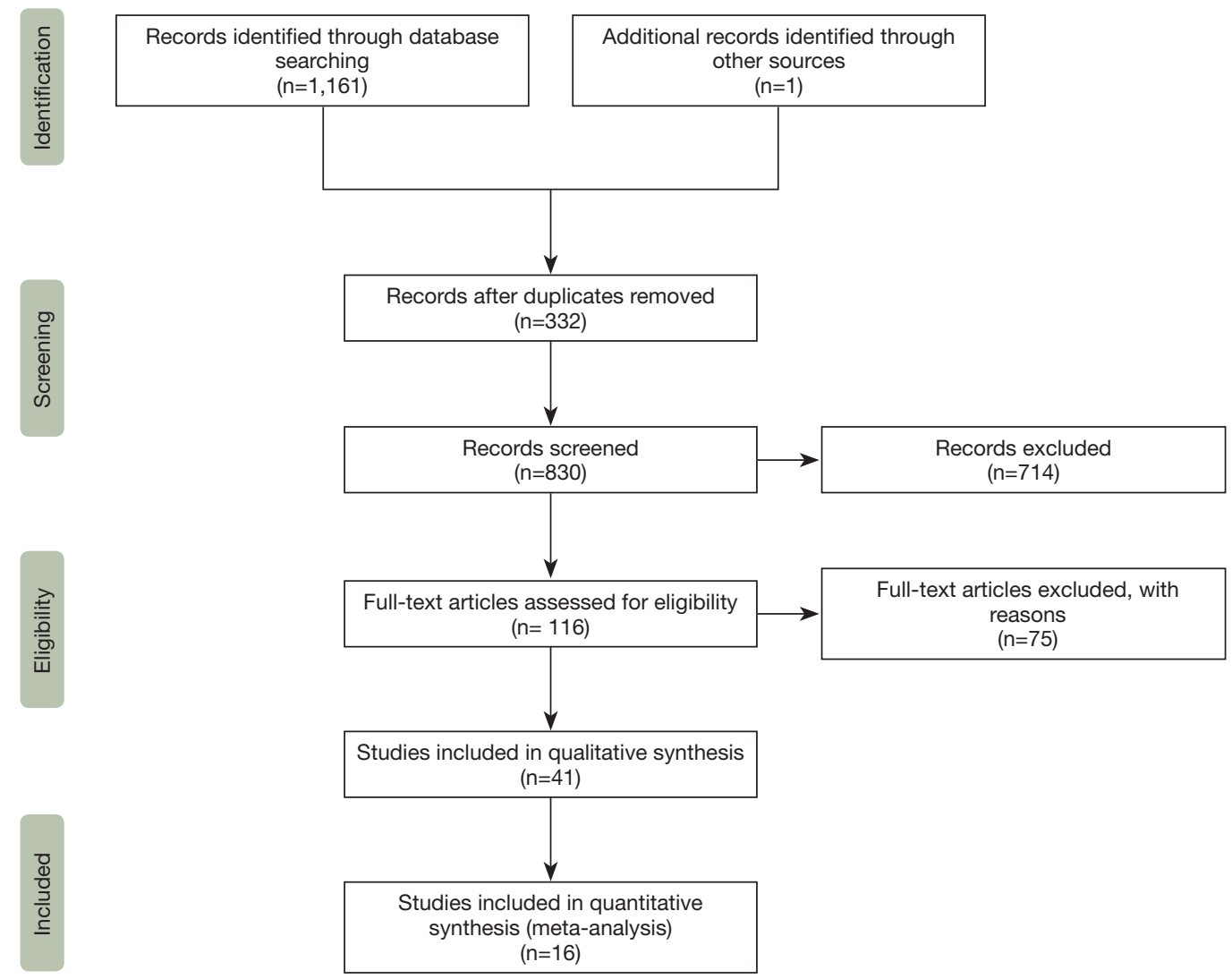

Figure 1 PRISMA flow diagram: search and selection of literature.

Heterogeneity was $0 \%$.

\section{Late mortality}

Four studies were included [Bernhardt 2011 (16), Coselli 2014 (18), Moreau de Bellaing 2019 (22), and Patel 2008 (24)]. The overall risk ratio was 0.35 (0.11-1.11). Heterogeneity was $0 \%$.

\section{Stroke}

Four studies were included [Bernhardt 2011 (16), Patel 2008 (24), Price 2016 (25), and Volguina 2009 (30)]. The overall risk ratio was $0.29(0.11-0.75)$, favoring VS interventions. Heterogeneity was $0 \%$.

\section{Aortic insufficiency (all grades)}

Two studies were included [Price 2016 (25) and Volguina 2009 (30)]. The overall risk ratio was 0.37 (0.09-1.52). Heterogeneity was $0 \%$.

\section{Endocarditis}

Three studies were included [Bernhardt 2011 (16), Coselli
2014 (18), and Price 2016 (25)]. The overall risk ratio was 0.13 (0.03-0.61), favoring VS interventions. Heterogeneity was $0 \%$ (Figure 2A,2B).

\section{Thromboembolic events}

After excluding Coselli 2014 (18) (which included embolic events in valves), two studies were included: Patel 2008 (24) and Price 2016 (25). The overall risk ratio was 0.19 (0.03-1.13). Heterogeneity changed from $36 \%$ to $0 \%$ after excluding Coselli 2014 (18) (Figure 3A,3B).

\section{Bleeding}

Four studies were included [Bernhardt 2011 (16), Patel 2008 (24), Price 2016 (25), and Volguina 2009 (30)]. The overall risk ratio was $0.51(0.17-1.47)$. Heterogeneity was $0 \%$.

\section{Arrhythmia}

Five studies were included [Bernhardt 2011 (16), Coselli 2014 (18), Patel 2008 (24), Price 2016 (25), and Volguina 2009 (30)]. The overall risk ratio was $0.74(0.52-1.04)$. Heterogeneity was $0 \%$. 
Table 2 Comparison of basal characteristics and outcome rates by type of surgical procedure

\begin{tabular}{|c|c|c|c|}
\hline Variable & Valve sparing procedure & Valve replacement procedure & $\mathrm{P}$ \\
\hline Number of studies & 33 & 26 & $\mathrm{~N} / \mathrm{A}$ \\
\hline Age (years), mean \pm SD & $33.3 \pm 3.3$ & $35.8 \pm 7.3$ & 0.0057 \\
\hline Male, n (\%) & $1,067 / 1,634(65.3)$ & $843 / 1,262(66.8)$ & 0.4201 \\
\hline Aortic diameter $(\mathrm{cm})$, mean $\pm \mathrm{SD}$ & $5.2 \pm 0.4$ & $6.2 \pm 0.7$ & 0.0232 \\
\hline Dissection, $\mathrm{n}(\%)^{\star}$ & $165 / 1,597$ (10.3) & $749 / 1,943(38.5)$ & $<0.001$ \\
\hline Aneurysm, n (\%)* & 1,181/1,262 (93.6) & $1,189 / 1,547(76.9)$ & $<0.001$ \\
\hline Person-years, median (IQR) & 129.5 (81.6-260.9) & $242.5(51.5-680.2)$ & 0.61 \\
\hline \multicolumn{4}{|l|}{ Rates per 10,000 person-years (median, IQR) } \\
\hline Late mortality & $0.3(0-2.8)$ & $2.3(0-4.4)$ & 0.187 \\
\hline Stroke & $0(0-0.2)$ & $0.5(0-1.1)$ & 0.084 \\
\hline Acute myocardial infarction & $0(0-0)$ & $0(0-0.5)$ & 0.424 \\
\hline Aortic insufficiency & $3.1(1.3-6.3)$ & $0.4(0-16.6)$ & 0.465 \\
\hline Endocarditis & $0(0-0)$ & $1.0(0.3-3.6)$ & 0.002 \\
\hline Thromboembolic events & $0(0-0.2)$ & $1.5(0.8-3.8)$ & 0.014 \\
\hline Bleeding & $0.1(0-1.9)$ & $2.2(0.6-5.5)$ & 0.082 \\
\hline Valve reintervention & $1.5(0.1-6.3)$ & $0.8(0-2.5)$ & 0.549 \\
\hline Survivors without acute myocardial infarction & $53.1(43.8-89.0)$ & $25.5(20.0-31.0)$ & ** \\
\hline Survivors without aortic insufficiency & $57.7(34.0-114.0)$ & $68.7(38.3-99.1)$ & ** \\
\hline Survivors without endocarditis & $79.0(57.1-102.0)$ & $14.6(12.2-16.7)$ & ** \\
\hline Survivors without thromboembolic events & $152.7(95.7-1596.8)$ & $26.7(21.8-31.6)$ & ** \\
\hline Survivors without bleeding & $77.5(56.9-97.6)$ & $17.2(13.4-26.8)$ & ** \\
\hline Survivors without valve reintervention & $34.5(25.6-86.3)$ & $38.9(12.4-185.4)$ & 0.881 \\
\hline Survivors without aneurysm & $53.1(43.8-67.0)$ & $36.4(24.2-468.0)$ & ** \\
\hline Survivors without dissection & $43.8(27.5-60.0)$ & $24.2(18.1-30.3)$ & ** \\
\hline Survivors without arrhythmia & $42.5(38.2-46.9)$ & $846.6(439.6-1,097.4)$ & ** \\
\hline
\end{tabular}

*, the percentages of patients with dissection and aneurysm within groups do not add up to $100 \%$ because these categories are not mutually exclusive (i.e., patients could have had both conditions). Additionally, denominators are not similar because not all studies included both types of patients or did not make this distinction; ${ }^{\star *}$, no studies available for direct comparison of such outcomes between groups. N/A, not applicable; SD, standard deviation; IQR, interquartile range. 
Table 3 Summary of studies included in the meta-analysis

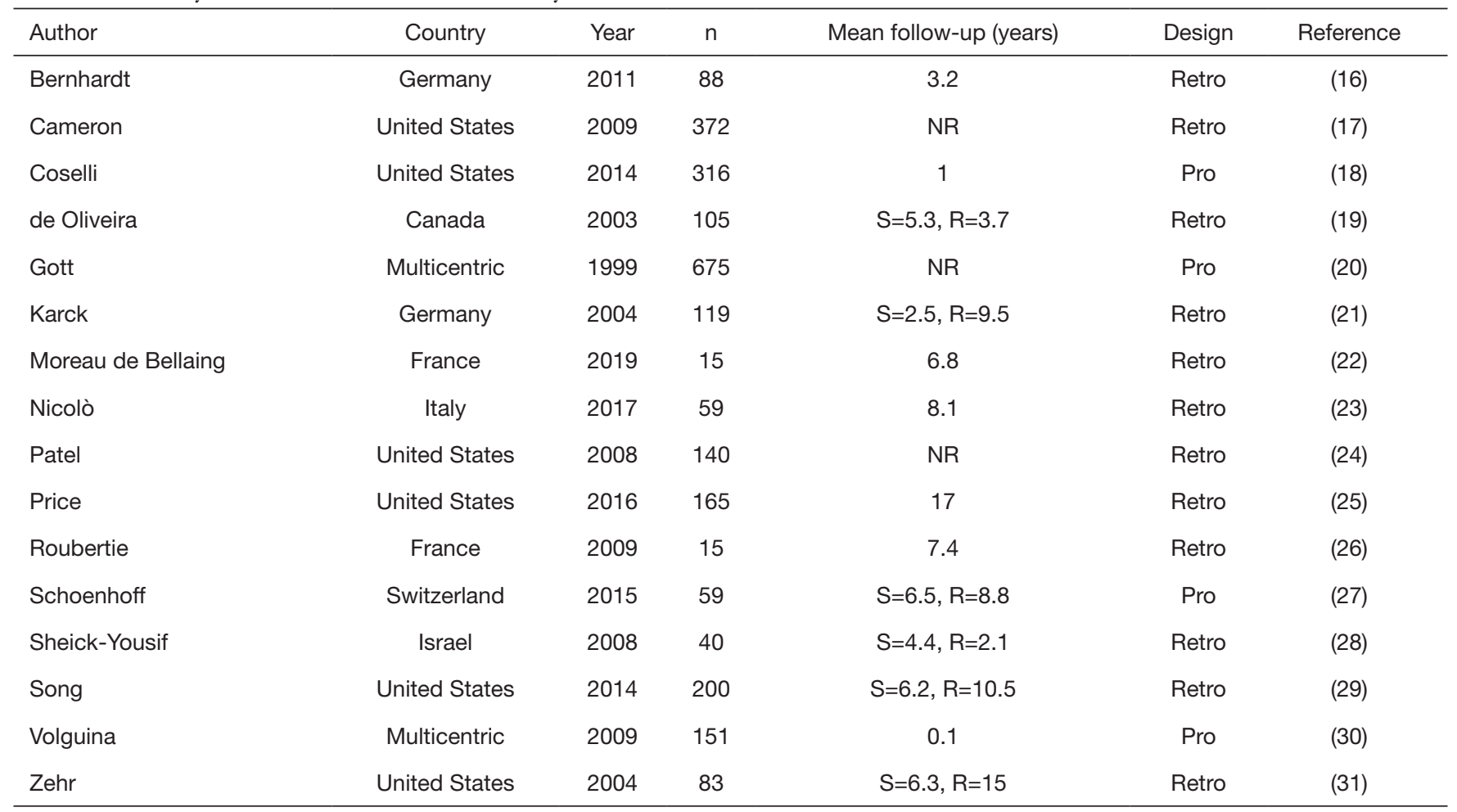

NR, not reported; VS, valve sparing procedure; VR, valve replacement procedure; Retro, retrospective; Pro, prospective.

A

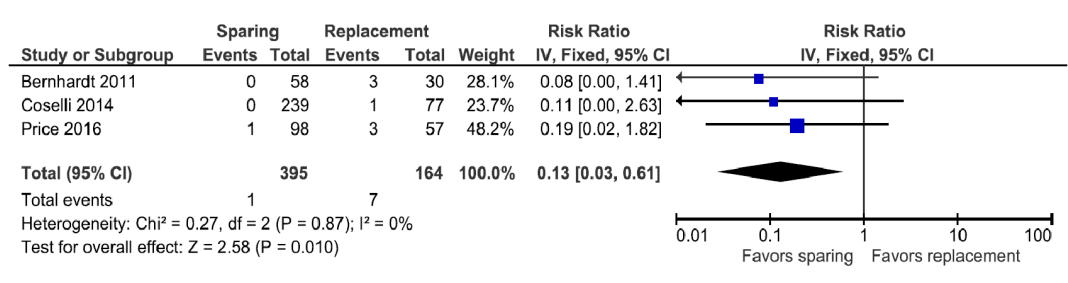

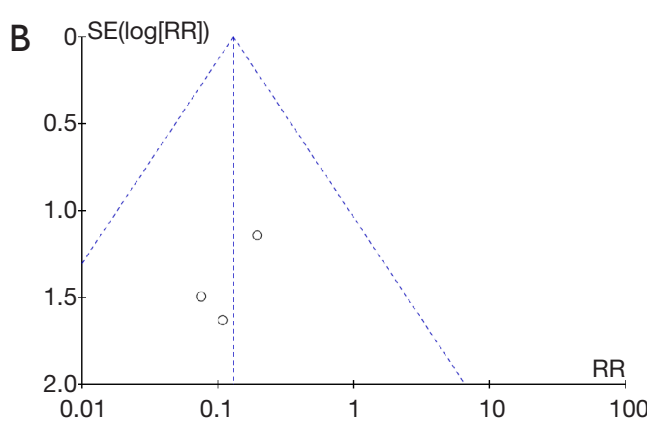

Figure 2 Results of the meta-analysis for endocarditis and funnel plot. (A) Comparison of endocarditis between patients operated with valve sparing versus replacement surgical techniques. (B) Publication bias for endocarditis.

\section{Valve reintervention}

Five studies were included [Bernhardt 2011 (16), Coselli 2014 (18), Moreau de Bellaing 2019 (22), Patel 2008 (24), and Price 2016 (25)]. The overall risk ratio was $0.79(0.31-$ 1.98). Heterogeneity was $17 \%$.

\section{Freedom from valve reintervention}

After excluding de Oliveira 2003 (19) (other causes of reintervention besides valvular reintervention) and Zehr
2005 (31) (different definitions of reintervention), five studies were included: Karck 2004 (21), Moreau de Bellaing 2019 (22), Nicolò 2017 (23), Patel 2008 (24), and SheickYousif 2008 (28). The overall risk ratio was 2.39 (1.24-4.60), favoring VR interventions. Heterogeneity changed from $57 \%$ to $0 \%$ after excluding de Oliveira 2003 (19) and Zehr 2005 (31) (Figure 4A,4B).

Funnel plots and Egger's test did not suggest publication bias except for the case of freedom from valve reintervention 
A
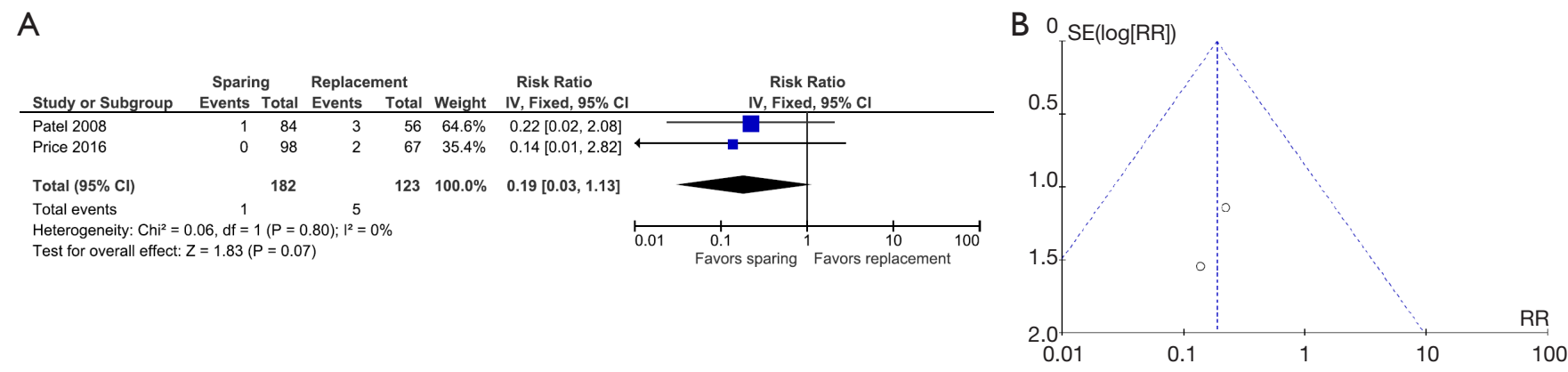

Figure 3 Results of the meta-analysis for thomboembolic events and funnel plot. (A) Comparison of thromboembolic events between patients operated with valve sparing versus replacement surgical techniques. (B) Publication bias for thromboembolic events.
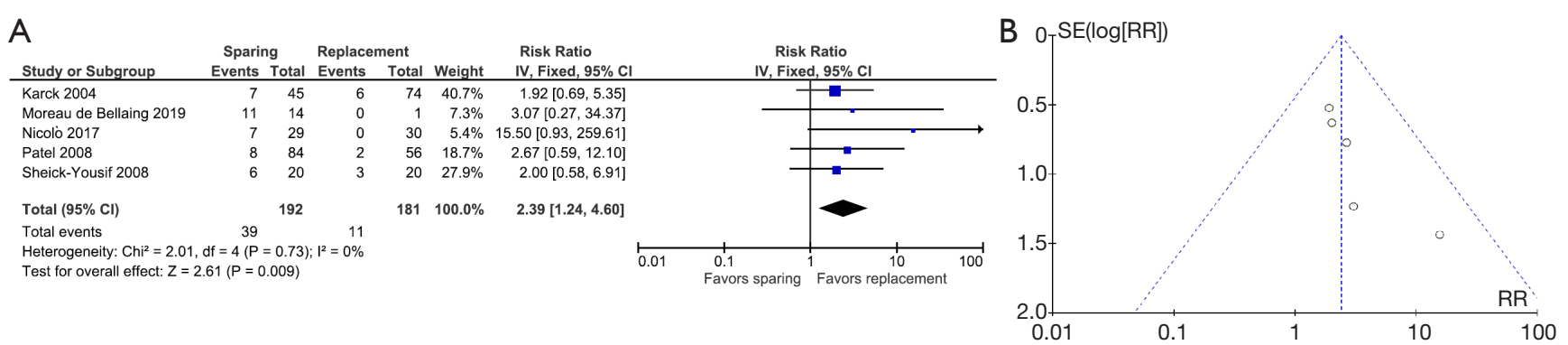

Figure 4 Results of the meta-analysis for freedom from valve reintervention and funnel plot. (A) Comparison of freedom from valve reintervention between patients operated with the valve sparing versus replacement techniques. (B) Publication bias for freedom from valve reintervention.

$(\mathrm{P}=0.022)$. Egger's test could not be calculated for aortic insufficiency and thromboembolic events, but the funnel plots did not suggest publication bias for any of these outcomes.

\section{Bias}

Bias was evaluated for the following domains: (I) randomization process, (II) deviations from intended interventions, (III) missing outcome data, (IV) measurement of the outcome, and (V) selection of the reported result. Our overall risk assessment concluded the presence of a low risk of bias in the observational studies included in the meta-analysis, considering that randomization did not apply to these cohort studies.

Comparisons adjusted to severity scores, aortic diameter and urgent surgery were not possible due to lack of individual data for subjects.

Table 4 shows the level of evidence using the Grading of Recommendations, Assessment, Development and Evaluation system (GRADE).

\section{Discussion}

Different techniques have been used to reconstruct the complex types of aortic dilation that patients with MFS and SS present. Experience in mastering each surgical technique is required since this is also a contributing factor in the prediction of different outcomes. Current European Society of Cardiology (ESC) guidelines on the diagnosis and treatment of acute and chronic aortic diseases of the thoracic and abdominal aorta of the adult recommend aortic valve reimplantation or aortic root remodeling with annuloplasty in young patients with tricuspid aortic valve morphology and aortic root aneurysm (34).

Initially, aortic valve-sparing surgery was used in patients with aortic root aneurysms, and aortic root replacement was reserved for patients with abnormal aortic leaflets. Subsequently, reimplantation and remodeling techniques began to be used due to the theoretical importance of recreating the aortic sinuses. Finally, aortic annuloplasty was added to the remodeling procedure in patients with annulo-aortic ectasia or MFS with the idea of preventing 


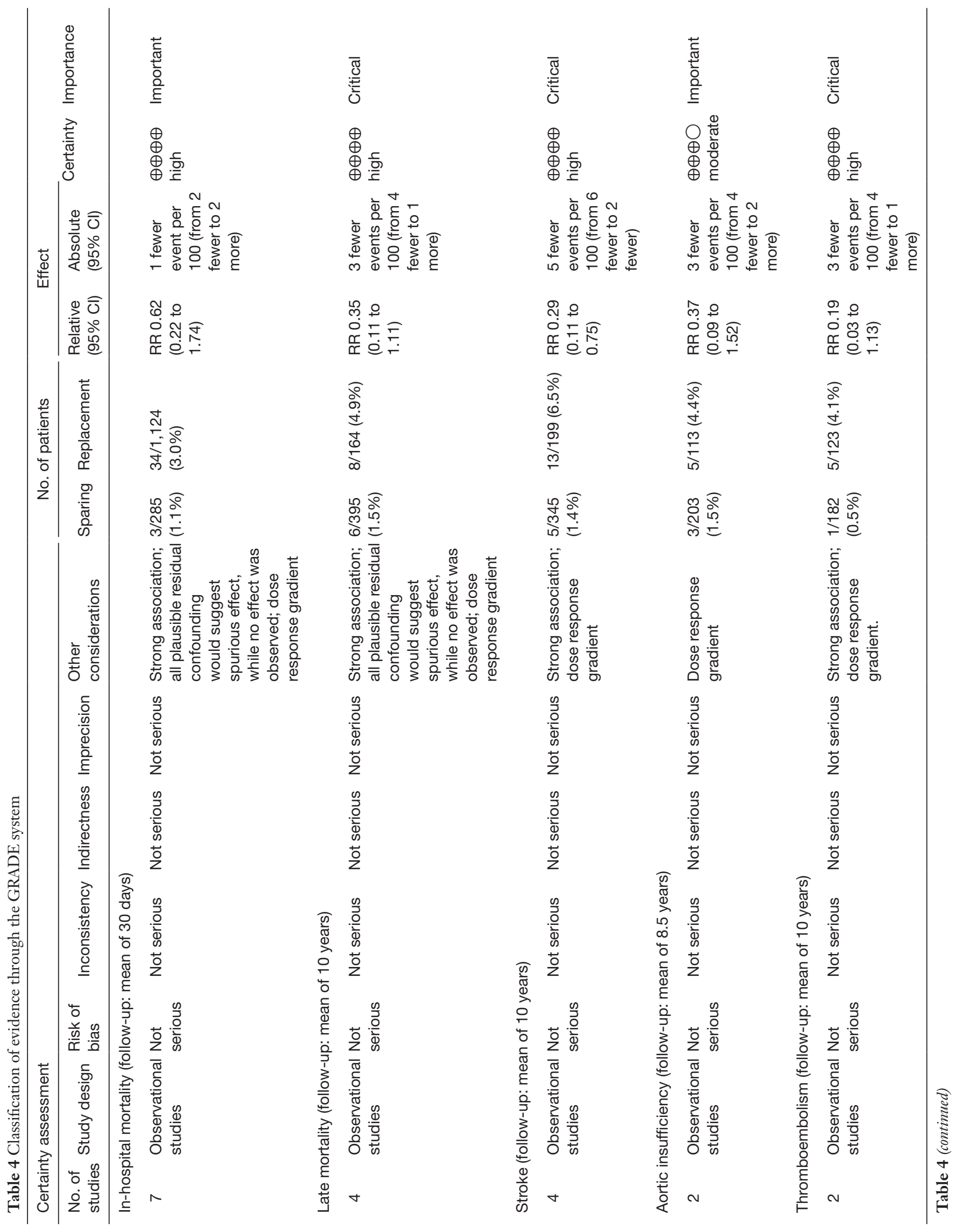




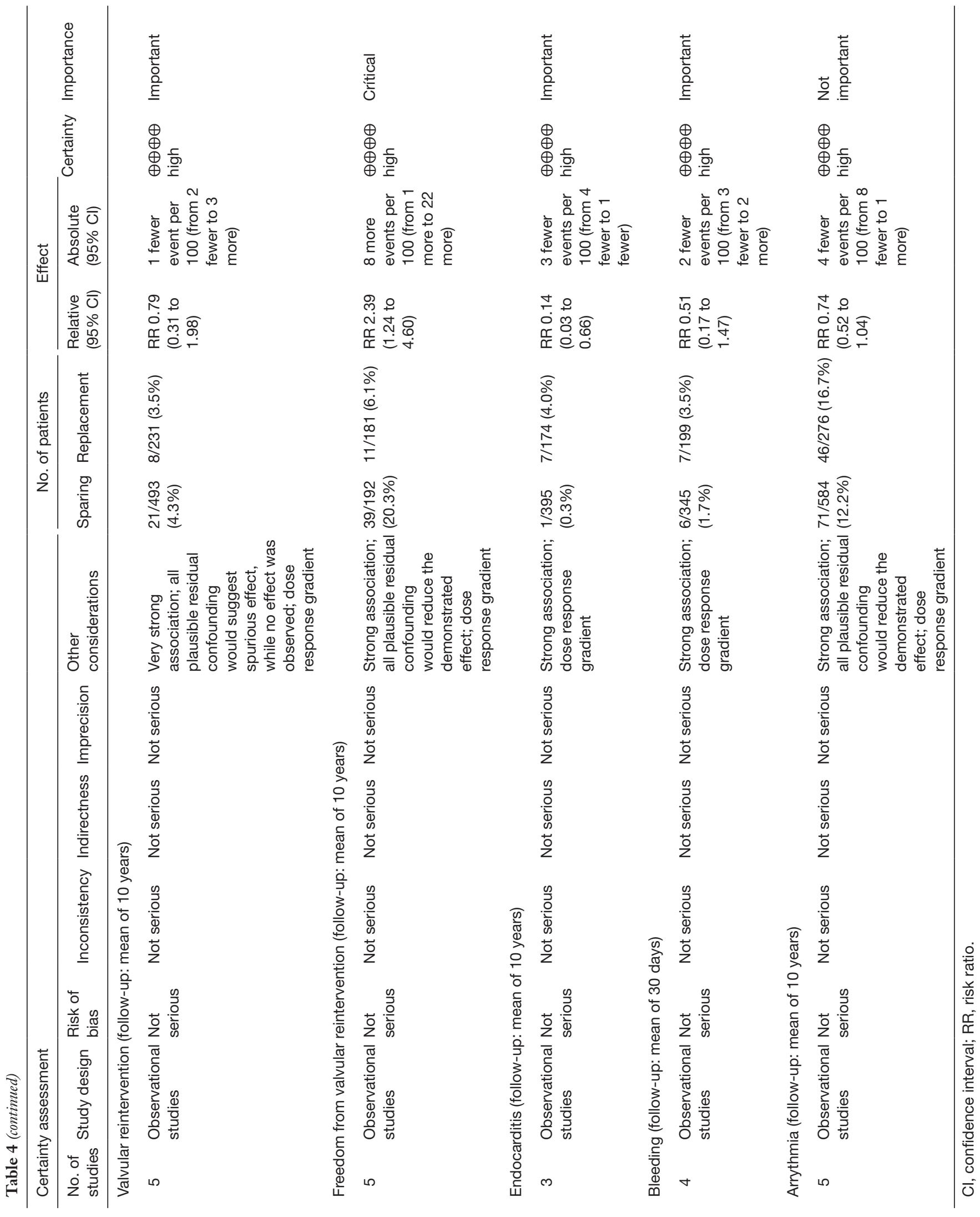


future dilation of the aortic annulus.

In the practice of contemporary cardiothoracic surgery, the most widely adopted and performed surgical approaches in patients with MFS with ascending aortic dilation are the Bentall, De Bono and David type $V$ techniques. These interventions are not comparable because the first approach is generally reserved for patients with aortic dilation and/ or dissection in severe condition or during episodes of acute aortic dissection, when surgical treatment is an emergency; on the other hand, techniques that preserve and repair the aorta are used more frequently in elective surgery and especially when there is no valve dysfunction.

The known long-term limitations of the Bentall technique are the need for lifelong anticoagulation and complications such as thromboembolism and endocarditis (34). On the other hand, the valve-sparing (VS) technique, which was introduced in 1990, as well as other techniques, perform repair of the aortic valve and allow the reconstruction of the aortic root and cusps with the aim of restoring normal geometry and valve competence.

The adaptations and modifications made through VS techniques are important because the recurrence of aortic insufficiency is related to a dilated annulus that was not treated when the diameters were greater than 25-28 $\mathrm{mm}$ and a residual cusp prolapse was present after root reconstruction, whether native or induced.

Urbanski (35) considered that adaptive root repair in isolated sinus replacement is an effective and long-lasting method of VS repair in selected patients with marfanoid habitus since satisfactory quality of the aortic cusps appeared to be decisive for long-term valve function.

Regarding the Florida Sleeve technique, only Volguina (30) included one patient. Although this technique is valve preserving, it is scarcely practiced in the world because it was recently introduced; since it involves a different approach, standardization and results of this technique will have to be evaluated in the future.

Remodeling procedures involve the repair of the annulus, the aorta and the valve leaflets, allowing the physiological reconstruction of the aortic root. Many reports of the experience with remodeling exist. Kunihara et al. (36) reported 33 MFS patients that had either the remodeling $(\mathrm{n}=21)$ or the reimplantation technique $(\mathrm{n}=12)$ between 1995 and 2011; results were similar among groups after matching by propensity score. Cameron et al. (17) reported that 5 of 40 patients that had the David II remodeling technique required reintervention due to aortic valve insufficiency as compared to no patients that underwent a David I procedure. In a series of 37 patients with MFS with a follow-up period of 13 years, Claudia Schmidtke reported that although the remodeling technique provided excellent results in 6 of 12 patients that had a Yacoub (remodeling) procedure, three required reoperation afterwards; thus, such technique could be associated with progressive aortic insufficiency (37). After studying 146 patients over 24 years of follow-up, Tirone E. David concluded that remodeling of the aortic root with an external band along the fibrous components of the left outflow tract seems inappropriate for MFS patients because the aortic annulus can dilate and cause aortic insufficiency years after the intervention; however, definite conclusions could not be drawn (38).

In the present meta-analysis, three articles reported results of the annuloplasty procedure. De Oliveira (19) reported the results of annuloplasty in 11 of 105 MFS patients in 2003 and he found an increase in annular diameter in the entire subgroup (from 23.1 to $24.8 \mathrm{~mm}$ ); besides, the annular diameter did not change in 11 patients and increased by $10 \%$ or more in 10 patients. However, a relationship between dilation of the aortic annulus and the development of aortic insufficiency could not be established due to a small sample size. Kremer et al. (39) found short-term success of annuloplasty in 13 of 56 patients, but long-term results are still unknown. Another author that reported his experience with annuloplasty is Vricella (40). He performed annuloplasty in 102 children over a period of 7 years and reported that VS can be done in pediatric patients with congenital heart disease or connective tissue disorders with minimal morbidity and mortality. The valvular and annular preservation and stabilization provided by reimplantation of the aortic valve within a graft with a pseudosinus can be a longerlasting alternative to a composite prosthetic replacement in children. Other case series of annuloplasty have shown that some patients developed dilated cardiomyopathy, moderate aortic insufficiency and cardiac dysfunction (22). It is currently known that external annuloplasty for valve replacement allows patients to be free of a valve-related reoperation for up to 7 years. The subvalvular remodeling and annuloplasty technique has been demonstrated by the CAVIAAR group (41).

The results of the present study are consistent with the work of $\mathrm{Hu}$ and colleagues published in 2014. The present meta-analysis included more recent studies, and its main strength is the systematic approach used to identify articles 
through a sensitive search strategy (42).

This meta-analysis confirms that the different techniques used in the repair of aortic dilation and/or dissection have a specific indication according to the complexity and state with which a patient presents to the surgeon. Recognition of the type of connective tissue disease is important since dilation progresses rapidly in some. Multidisciplinary intervention is the best prospect for a successful and timely surgical intervention. Current guidelines suggest intervening these patients when aortic diameters are less than $5 \mathrm{~cm}$, but the best choice of surgical technique will be subject to individual cardiovascular complexities. VS surgery favors patients that have the opportunity of an elective procedure, but replacement surgery continues to provide excellent results in patients that need a salvage surgery due to delayed diagnosis or inappropriate follow-up. In the end, while the choice of the technique or procedure depends largely on the experience of the surgeon, it also depends on the type of patient, his/her age and gender (considering pregnancy a possibility), occupation or lifestyle, possibility of aortic annulus dilation or aortic engorgement (through the evaluation of the morphology of the aortic root and the condition of the leaflets), and the viability to receive anticoagulation.

The recognized limitation of this study is the impossibility of finding large prospective cohort studies in which similar methodological strategies were carried out with each of the surgical techniques, as well as the lack of randomization in the studies included. Another limitation was the absence of a differential reporting of outcomes based on clinical presentation (aneurysm versus dissection or urgent versus elective procedure).

\section{Conclusions}

Timely identification of MFS and other connective tissue diseases, the type of aortic and cardiovascular damage, and specific patient conditions are key factors when choosing the surgical technique. The results of this meta-analysis could guide future prospective studies aimed at offering the best surgical, interventional or hybrid interventions in patients with these syndromes. This is important because scientific evidence uncovers biases and heterogeneity that can be reduced with better patient selection and a systematic methodology that could otherwise be overlooked if only surgeon experience is relied upon. Aortic and cardiovascular damage is complex and heterogeneous in patients with connective tissue diseases, so even when the evidence suggests a course of action and choice with a particular surgical technique, the surgeon is the one that faces the challenge of the final decision during the surgical act.

\section{Acknowledgments}

We thank DHS for her valuable help with proofreading. Funding: None.

\section{Footnote}

Reporting Checklist: The authors have completed the PRISMA reporting checklist. Available at https://dx.doi. org/10.21037/jtd-21-789

Peer Review File: Available at https://dx.doi.org/10.21037/ jtd-21-789

Conflicts of Interest: All authors have completed the ICMJE uniform disclosure form (available at https://dx.doi. org/10.21037/jtd-21-789). The authors have no conflicts of interest to declare.

Ethical Statement: The authors are accountable for all aspects of the work in ensuring that questions related to the accuracy or integrity of any part of the work are appropriately investigated and resolved.

Open Access Statement: This is an Open Access article distributed in accordance with the Creative Commons Attribution-NonCommercial-NoDerivs 4.0 International License (CC BY-NC-ND 4.0), which permits the noncommercial replication and distribution of the article with the strict proviso that no changes or edits are made and the original work is properly cited (including links to both the formal publication through the relevant DOI and the license). See: https://creativecommons.org/licenses/by-nc-nd/4.0/.

\section{References}

1. Loeys B, De Backer J, Van Acker P, et al. Comprehensive molecular screening of the FBN1 gene favors locus homogeneity of classical Marfan syndrome. Hum Mutat 2004;24:140-6.

2. Abdelrahim $M$, Nimir $M$, Abdalla $M$, et al. Review of FBN1 Gene Role in Marfan Syndrome Presentations 
Insilico Analysis. Am J Biomed Res 2016;4:5-12.

3. Zeyer KA, Reinhardt DP. Engineered mutations in fibrillin-1 leading to Marfan syndrome act at the protein, cellular and organismal levels. Mutat Res Rev Mutat Res 2015;765:7-18.

4. Aragon-Martin JA, Child AH. Marfan syndrome (MFS): Inherited microfibrillar disorder caused by mutations in the fibrillin-1 gene. In: Diagnosis and Management of Marfan Syndrome. Springer-Verlag London Ltd, 2016:233-44.

5. Williams JA, Loeys BL, Nwakanma LU, et al. Early surgical experience with Loeys-Dietz: a new syndrome of aggressive thoracic aortic aneurysm disease. Ann Thorac Surg 2007;83:S757-63; discussion S785-90.

6. Pope FM, Martin GR, Lichtenstein JR, et al. Patients with Ehlers-Danlos syndrome type IV lack type III collagen. Proc Natl Acad Sci U S A 1975;72:1314-6.

7. Pepin MG, Schwarze U, Rice KM, et al. Survival is affected by mutation type and molecular mechanism in vascular Ehlers-Danlos syndrome (EDS type IV). Genet Med 2014;16:881-8.

8. Frank M, Albuisson J, Ranque B, et al. The type of variants at the COL3A1 gene associates with the phenotype and severity of vascular Ehlers-Danlos syndrome. Eur J Hum Genet 2015;23:1657-64.

9. Cooley DA. Aortic aneurysm operations: past, present, and future. Ann Thorac Surg 1999;67:1959-62; discussion 1979-80.

10. MUELLER A. The aortic wall deserves special attention. Bull Schweiz Akad Med Wiss 1960;16:210-20.

11. Wheat MW, Wilson JR, Bartley TD. Successful Replacement of the Entire Ascending Aorta and Aortic Valve. JAMA 1964;188:717-9.

12. Bentall H, De Bono A. A technique for complete replacement of the ascending aorta. Thorax 1968;23:338-9.

13. David TE, Feindel CM. An aortic valve-sparing operation for patients with aortic incompetence and aneurysm of the ascending aorta. J Thorac Cardiovasc Surg 1992;103:61721; discussion 622.

14. von Elm E, Altman DG, Egger M, et al. The Strengthening the Reporting of Observational Studies in Epidemiology (STROBE) statement: guidelines for reporting observational studies. J Clin Epidemiol 2008;61:344-9.

15. Moher D, Liberati A, Tetzlaff J, et al. Preferred reporting items for systematic reviews and meta-analyses: the PRISMA statement. PLoS Med 2009;6:e1000097.

16. Bernhardt AM, Treede H, Rybczynski M, et al.
Comparison of aortic root replacement in patients with Marfan syndrome. Eur J Cardiothorac Surg 2011;40:1052-7.

17. Cameron DE, Alejo DE, Patel ND, et al. Aortic root replacement in 372 Marfan patients: evolution of operative repair over 30 years. Ann Thorac Surg 2009;87:1344-9; discussion 1349-50.

18. Coselli JS, Volguina IV, LeMaire SA, et al. Early and 1-year outcomes of aortic root surgery in patients with Marfan syndrome: a prospective, multicenter, comparative study. J Thorac Cardiovasc Surg 2014;147:1758-66, 1767.e1-4.

19. de Oliveira NC, David TE, Ivanov J, et al. Results of surgery for aortic root aneurysm in patients with Marfan syndrome. J Thorac Cardiovasc Surg 2003;125:789-96.

20. Gott VL, Greene PS, Alejo DE, et al. Replacement of the aortic root in patients with Marfan's syndrome. N Engl J Med 1999;340:1307-13.

21. Karck M, Kallenbach K, Hagl C, et al. Aortic root surgery in Marfan syndrome: Comparison of aortic valve-sparing reimplantation versus composite grafting. J Thorac Cardiovasc Surg 2004;127:391-8.

22. Moreau de Bellaing A, Pontailler M, Bajolle F, et al. Ascending aorta and aortic root replacement (with or without valve sparing) in early childhood: surgical strategies and long-term outcomes. Eur J Cardiothorac Surg 2020;57:373-9.

23. Nicolo F, Romeo F, Lio A, et al. Long-Term Results of Aortic Root Surgery in Marfan Syndrome Patients: A Single-Center Experience. J Heart Valve Dis 2017;26:397-404.

24. Patel ND, Weiss ES, Alejo DE, et al. Aortic root operations for Marfan syndrome: a comparison of the Bentall and valve-sparing procedures. Ann Thorac Surg 2008;85:2003-10; discussion 2010-1.

25. Price J, Magruder JT, Young A, et al. Long-term outcomes of aortic root operations for Marfan syndrome: A comparison of Bentall versus aortic valve-sparing procedures. J Thorac Cardiovasc Surg 2016;151:330-6.

26. Roubertie F, Ben Ali W, Raisky O, et al. Aortic root replacement in children: a word of caution about valve-sparing procedures. Eur J Cardiothorac Surg 2009;35:136-40.

27. Schoenhoff FS, Langhammer B, Wustmann K, et al. Decision-making in aortic root surgery in Marfan syndrome: bleeding, thromboembolism and risk of reintervention after valve-sparing or mechanical aortic root replacement. Eur J Cardiothorac Surg 2015;48:931-5; discussion 935-6. 
28. Sheick-Yousif B, Sheinfield A, Tager S, et al. Aortic root surgery in Marfan syndrome. Isr Med Assoc J 2008;10:189-93.

29. Song HK, Preiss LR, Maslen CL, et al. Valve-sparing aortic root replacement in patients with Marfan syndrome enrolled in the National Registry of Genetically Triggered Thoracic Aortic Aneurysms and Cardiovascular Conditions. J Heart Valve Dis 2014;23:292-8.

30. Volguina IV, Miller DC, LeMaire SA, et al. Valve-sparing and valve-replacing techniques for aortic root replacement in patients with Marfan syndrome: Analysis of early outcome. J Thorac Cardiovasc Surg 2009;137:1124-32.

31. Zehr KJ, Orszulak TA, Mullany CJ, et al. Surgery for aneurysms of the aortic root: a 30-year experience. Circulation 2004;110:1364-71.

32. Hu R, Wang Z, Hu X, et al. Effect of native aortic valve sparing aortic root reconstruction surgery on shortand long-term prognosis in Marfan syndrome patients:a meta-analysis. Zhonghua Xin Xue Guan Bing Za Zhi 2014;42:433-8.

33. Nardi P, Pellegrino A, Versaci F, et al. Aortic root surgery in Marfan syndrome: Bentall procedure with the composite mechanical valved conduit versus aortic valve reimplantation with Valsalva graft. J Cardiovasc Med (Hagerstown) 2010;11:648-54.

34. Erbel R, Aboyans V, Boileau C, et al. 2014 ESC Guidelines on the diagnosis and treatment of aortic diseases: Document covering acute and chronic aortic diseases of the thoracic and abdominal aorta of the adult. The Task Force for the Diagnosis and Treatment of Aortic Diseases of the European Society of Cardiology (ESC). Eur Heart J 2014;35:2873-926.

Cite this article as: Soto ME, Ochoa-Hein E, Anaya-Ayala JE, Ayala-Picazo M, Koretzky SG. Systematic review and metaanalysis of aortic valve-sparing surgery versus replacement surgery in ascending aortic aneurysms and dissection in patients with Marfan syndrome and other genetic connective tissue disorders. J Thorac Dis 2021;13(8):4830-4844. doi: 10.21037/jtd21-789
35. Urbanski PP, Jankulowski A, Morka A, et al. Patienttailored aortic root repair in adult marfanoid patients: Surgical considerations and outcomes. J Thorac Cardiovasc Surg 2018;155:43-51.e1.

36. Kunihara T, Rodionycheva S, Aicher D, et al. Longterm outcome after valve-preserving root surgery for patients with Marfan Syndrome. Thorac Cardiovasc Surg 2012;60:77.

37. Schmidtke C, Karluss A, Sier H, et al. Mid-term results of different aortic valve-sparing procedures in Marfan syndrome. J Heart Valve Dis 2012;21:195-201; discussion 202.

38. David TE, David CM, Manlhiot C, et al. Outcomes of Aortic Valve-Sparing Operations in Marfan Syndrome. J Am Coll Cardiol 2015;66:1445-53.

39. Kremer J, Farag M, Zaradzki M, et al. The reimplantation valve-sparing aortic root replacement technique for patients with Marfan syndrome: A single-center experience. Sci Rep 2019;9:12021.

40. Vricella LA, Williams JA, Ravekes WJ, et al. Early experience with valve-sparing aortic root replacement in children. Ann Thorac Surg 2005;80:1622-6; discussion 1626-7.

41. Lansac E, Bouchot O, Arnaud Crozat E, et al. Standardized approach to valve repair using an expansible aortic ring versus mechanical Bentall: early outcomes of the CAVIAAR multicentric prospective cohort study. J Thorac Cardiovasc Surg 2015;149:S37-45.

42. Song F, Parekh S, Hooper L, et al. Dissemination and publication of research findings: an updated review of related biases. Health Technol Assess 2010;14:iii, ix-xi, 1-193. 